\title{
Trap in the Closet: Intra-Ethnic Marriage and Intimate Partner Violence in Sub-Saharan Africa
}

\author{
Akpovire Oduaran ${ }^{1}$ and Okechukwu Chukwudeh ${ }^{1,2, * \mathbb{D}}$ \\ 1 Community-Based Educational Research (COMBER), Faculty of Education, North-West University, \\ Potchefstroom 2520, South Africa; akpovire.oduaran@nwu.ac.za \\ 2 Department of Criminology and Security Studies, Faculty of Social Sciences, Federal University, \\ Oye-Ekiti, Nigeria \\ * Correspondence: stivchuks@gmail.com
}

Citation: Oduaran, Akpovire, and Okechukwu Chukwudeh. 2021. Trap in the Closet: Intra-Ethnic Marriage and Intimate Partner Violence in Sub-Saharan Africa. Social Sciences 10

31. https://doi.org/10.3390/socsci 10020031

Received: 30 November 2020 Accepted: 23 December 2020 Published: 21 January 2021

Publisher's Note: MDPI stays neutral with regard to jurisdictional clai$\mathrm{ms}$ in published maps and institutional affiliations.

Copyright: (C) 2021 by the authors. Licensee MDPI, Basel, Switzerland. This article is an open access article distributed under the terms and conditions of the Creative Commons Attribution (CC BY) license (https:// creativecommons.org/licenses/by/ $4.0 /)$.

\begin{abstract}
Intimate partner violence is a threat to achieving Sustainable Development Goal 5 by 2030. The challenge of intimate partner violence is prevalent among immigrants. However, little is known about the peculiarity of intimate partner violence in intra-ethnic marriages, especially among immigrants within sub-Saharan Africa. This study examined the factors contributing to intimate partner violence among Senegalese immigrants who live in Nigeria. It also examined the extent of intimate partner violence in intra-ethnic marriages. Referrals and exponential non-discriminative snowball sampling were utilized to interview 20 participants. Results show that social factors such as gender norms, cultural norms, patriarchy, and economic challenges were the major factors contributing to intimate partner violence among Senegalese immigrants living in Nigeria. Marriage to someone from the same ethnic group does not prevent intimate partner violence as the factors contributing to this social problem are not exclusive to ethnic group affiliation. Informal measures such as ethnic group association and neighborhood assistance are the measures used to resolve household violence among immigrants. Contextually, programs aimed at reducing and stopping intimate partner violence should incorporate the support of informal groups and community leaders who are the custodians of culture in the society.
\end{abstract}

Keywords: intimate partner violence; intra-ethnic marriage; patriarchy; social norms; sub-Saharan Africa

\section{Introduction}

Violence against women is a social problem with severe implications for the progress, growth, and development of a country. Globally, one-third of women have experienced intimate partner violence at a point in time (WHO 2015). Widespread intimate partner violence (IPV) is a violation of the proper well-being and development of women. Intimate partner violence is a form of domestic violence. Some studies (Devries et al. 2013; Ranganathan et al. 2019) have reported adverse effects of IPV to include physical damages such as bruises, dislocation, joint pain, broken bones, and blindness. Other studies (Zembe et al. 2015; WHO 2015) have associated IPV with rape, depression, suicide, sexually transmitted diseases (STDs), mental stress, sexual abuse, insecurity, death, and transmission of HIV / AIDS. Abuse against women affects the balance and peace within a community. This is because IPV leads to strained family relationships, divorce, and an increased death rate of women estimated at 8.8 per 100,000 (Allsworth and Goldman 2017).

The prevalence of IPV remains high despite concerted efforts to reduce it. For instance, WHO (2017) reported that 35\% of women experience IPV globally. In Africa, at least $40 \%$ of married women had experienced IPV (WHO 2013). The prevalence of intimate partner violence in sub-Saharan Africa remains unclear. A noticeable occurrence is that male children who grow up in a home where violence against women is common are likely to be violent against women (Gage 2005; McCloskey et al. 2016). Surprisingly, many women 
justify violence against women due to patriarchy and cultural norms that place men as superior above women. Violence against women can be physical, emotional, mental, social, sexual, and include all forms of coercive control (Stark 2007). Physical violence can be exerted by the use of masculine strength to beat and injure the woman, thereby causing physical injuries like broken bones, swollen face, and other injuries. Sexual violence can be exerted through forced sexual intercourse, and emotional violence through verbal abuse.

Intimate partner violence has adverse emotional and health outcomes for women. The precarious health implications of IPV are quantum, and it is an impediment to achieving gender equality as enshrined in Sustainable Development Goal 5. The threat is high in a patriarchal society where cultural hegemony permits male dominance over females (Chikhungu et al. 2019). The bane of the situation is that IPV is often underreported, as many victims do not want to be associated with it due to shame and cultural norms. Yet more than half of married women are likely to experience intimate partner violence (IPV) during their lifetimes (Devries et al. 2013). This in turn can increase the prevalence of depression, loneliness, promiscuity, STD, and HIV / AIDS (Ranganathan et al. 2019). The gravity of intimate partner violence was captured at the World Conference on Human Rights in Vienna, which was held in 1993 with the aim of eliminating all forms of violence against women. Despite such efforts, the prevalence of intimate partner violence is still high and widely underreported.

Stark (2007) posited that intimate partner violence, which is one form of domestic violence, is neither primarily domestic nor necessarily violent, but a pattern of controlling behaviors. Domestic violence is a coercive strategy that men use to deny females their personhood. For Stark (2007), it was ideal to look at intimate partner violence from the perspective of victimization that leads to violations of women's rights. He further succinctly explained why women remain in marriage despite domestic violence. He stressed how power inequality aids male coercive control over females. Scholars (Stark 2016; Walby and Towers 2017; Bishop and Bettinson 2018) have acknowledged that coercive control comes in different forms, such as physical abuse and intimidation; controlling women's time, diet, finances, socialization, dress and grooming, religious beliefs; emotional abuse; sexual abuse; constraining women from working secularly; and controlling their career development.

Previous studies have reported that intimate partner violence, household conflict, and divorce were only predominant in inter-ethnic marriages (Fryer 2007; Hohman-Marriott and Amato 2008). Encapsulating this report is the knowledge that the choice of marriage in Africa is influenced by ethnicity and cultural practices (Magadi et al. 2020). In addition, the type of marriage, size of family, and practices within the family are influenced by cultural practices. Yet little is known about how culture influences the incidence of intimate partner violence in Africa. This study examined the influence of intra-ethnic marriage on intimate partner violence, using a qualitative method to understand the causes of gender-based violence in the family. The overarching research objective was to examine the incidence of intimate partner violence within intra-ethnic marriage among immigrants in Africa using the experiences of Senegalese women living in Nigeria as a reflection. Specific research questions addressed in this study are: (1) What are the factors contributing to intimate partner violence among Senegalese immigrants living in Nigeria? (2) To what extent do ethnicity and intra-ethnic marriage influence the practice of intimate partner violence among immigrants?

\section{Feminist Theory}

Society socially constructs gender roles and practices. Feminist theorists posit that inequality exists between males and females, which often leads to female exploitation by the male. The exploitation that females experience from the male gender is associated with patriarchy and power relations within the society (Abbott et al. 2005). Over the years, various forms of oppression that have been embedded in the society's values and norms have passed from one generation to another through socialization and the practice of 
patriarchy, especially in sub-Saharan Africa. Radical feminism views men as the ruling class and women as the subject class. For radical feminism, the family institution has been designed as the superstructure that permits and sustains male exploitation of the female. In fact, earlier proponents of radical feminism posit that male domination over female is biological, and that male violence toward women is a systematic way to maintain power. This gender-power relation is possible in societies where cultural norms are highly valued. These dominations can be seen in male domination over female; women being associated with the kitchen and reproductive duties; patriarchal culture and practices; patriarchal relations within the household; sexualities and other female ascribed roles (Conway 2016; Cockburn 2004). Studies have shown that the patriarchal power structure in the society serves as superstructure that sustains male domination over female (Corradi et al. 2016). However, the practice of patriarchy is contextual, and it is not universally applicable, and differs within time and space.

\section{Materials and Methods}

\subsection{Design and Settings}

This qualitative design was cross-sectional as data were collected once-at a point in time. This design was necessary to explore the experiences of immigrant women from Senegal who migrated to and resided in Nigeria. The study was conducted in Southwest Nigeria (Oyo state, Ibadan). The location was selected due to the strategic concentration of Senegalese who settled down there with their families before advancing in search of gold in other nearby villages. The following research questions guided this study: What are the factors contributing to intimate partner violence among Senegalese migrants living in Nigeria? To what extent does intra-ethnic marriage influence the incidence of intimate partner violence? This study examined (1) the factors contributing to intimate partner violence among Senegalese women living in Nigeria, and (2) the extent to which intra-ethnic marriage influences the occurrence of intimate partner violence in sub-Saharan Africa. Feminist theory served as a guide to providing answers to the above research questions.

\subsection{Study Participants}

Twenty participants were selected for the study using intentional sampling. The sample size was determined through theoretical saturation. The selected participants were those who met the following inclusion criteria: must be a Senegalese, must be married, must be 18 years and above, must have lived in Nigeria for at least 10 years, must have experienced intimate partner violence, must be mentally sound to understand the purpose of the study, and must be willing to participate in the study. Eligible participants were recruited with the help of an influential Senegalese woman leader in the community. Since the immigrant lives within a homogenous group, the researcher sought and got verbal approval from the woman leaders. The woman leader introduced the researchers to other Senegalese women, and those who had experienced intimate partner violence were sought through referral and exponential non-discriminative snowball sampling. Face-to-face interviews were conducted with the participants.

\subsection{Discussion Guides}

The study applied a qualitative approach for collecting data with the use of a semistructured in-depth interview (IDI) guide. The topics covered by the interview guide were: benefits of marrying someone from the same ethnic group, experiences of intimate partner violence, factors contributing to intimate partner violence, reasons for not leaving the marriage, and solutions to intimate partner violence. The interview guide was piloted with female immigrants who lived in the Egbeda Local Government area in Oyo State Nigeria, and modified by the researchers to suit the objectives of the study. The piloted interview guide assisted the researchers to know what to anticipate from participants. This helped to safeguard against emotional and mental harm. This method had earlier been used by Goodrum and Keys (2007) when engaging in sensitive research issues. The researchers first 
discussed different strategies of coping in a foreign land with the participants to establish a relationship with them. Then the researchers probed into their choice of marriage and experiences of intimate partner violence. The participants were from 20 to 56 years old, and the interview was conducted from June to July 2019. Comments from the respondents were recorded with an audiotape recorder. Field notes were used to jot down points after requesting permission from the participants. The themes that formed the objectives of the study were derived from the responses of the respondents. The total duration of each interview ranged from 40 to $60 \mathrm{~min}$. The interviews ended after data saturation. All interviews were conducted at a private home. The researchers ensured that only the participants were around at home during interviews.

\section{Data Collection Procedures}

An in-depth interview (IDI) was conducted with 20 female participants who had been living in Nigeria for at least 10 years. The respondents were purposively selected through referral and exponential non-discriminative snowball sampling. After each face-to-face interview, the researchers requested a referral to anyone who met the inclusion criteria and had experienced violence at home. Despite referrals, one person refused to take part in the research because of fear of the unknown. The researchers, therefore, informed all respondents that this was purely an academic exercise. This continued until data saturation, when new ideas were not forthcoming. For this study, two female research assistants were recruited and trained in data collection procedures. One of the female research assistants was a Nigerian, while the other was a Senegalese who had lived in Nigeria for a long period. The discussion was conducted in Pidgin English and Wolof language simultaneously, using a guide with a list of open-ended questions to allow the participants to express their opinions. All data were transcribed into the English language by the research team. All discussions were audio-recorded with the consent of the participants, and the IDI was conducted between June and July 2019.

\section{Data Analyses}

The thematic analysis approach as suggested by Braun and Clarke (2006) was used for this study. Data generated from the field were qualitatively analyzed, which resulted in themes and sub-themes. Based on the grounded theory (Charmaz and Henwood 2017), themes were generated from the experiences and narratives of participants (data). This enabled the researchers to compare and contrast data in order to describe the relationship between themes. The researchers were involved in coding using Microsoft Word. An initial line by line open coding was used to categorize and summarize the data (Berg 2001), followed by more focused coding centered on the significant codes and categories that tended to be more conceptual. This facilitated comparative analysis aimed at comparing data to data and data to codes and categories to identify similarities and differences. The thematic analysis was done using an inductive method as themes were developed from data generated from the field. First, code was generated from data. When a group of codes was repeated in a particular way, it became a theme. Themes were developed by the compare and contrast approach, which entailed a line by line analysis of words, sentences, and content. Each line was read, and contextual meaning deduced. This was followed by sentence to word, and sentence to sentence analysis to know how one word and sentence differed from the preceding word and sentence, and the meaning therein. Pairs of text were compared to know their contextual meaning among the Senegalese. This method made the data analyses robust.

\section{Ethical Consideration}

Ethical approval was sought from the University of Ibadan Social Sciences and Humanities Research Ethics Committee, University of Ibadan, Nigeria, with the assigned number UI/SSHEC/2017/0025. In addition, the international standard ethical issues bearing on respondent confidentiality, beneficence to participants, non-maleficence, and 
justice as it affected the study were considered and respected. To ensure anonymity, all respondents and participants were labeled " $W$ ".

Besides these general ethical principles, violence research posed specific challenges that required particular consideration, such as the safety of the respondents and the interviewers, which were incorporated in all decisions of this research. The World Health Organisation has considered issues bearing on safety, which led to different recommendations for addressing appropriate safety and ethical issues in family violence research (WHO 2001, 2003, 2007). The effects of these guidelines on research on family violence have been well documented (Ellsberg et al. 2001; Btoush and Campbell 2009).

The researchers overcame the challenges associated with the collection of data on violence research in the following ways. The influential Senegalese woman leader, who gave verbal approval for the study, introduced the female research assistants to the Senegalese women. This was done individually and privately in the female unit of the central mosque at the study location. Thereafter, a strategic arrangement was made and signs symbolizing actions were communicated to the women. First, on the specific date and time of each appointment, the Senegalese female research assistant was delegated to put a call through to the respondent via mobile voice call to learn if it was appropriate to visit. The respondent was meant to reply immediately, "Hope the price has fallen/reduce." That response signified that it was safe and appropriate for the research team to visit. Immediately after such approval, the waiting research team moved to the respondent's home and conducted the interview. However, if it was not safe and appropriate to visit the respondent, probably due to the presence of her husband, the respondent was meant to reply as soon as she took the call, "I will not purchase today", or she would cough twice as soon as she answered the call, just before saying hello. By that signal, the research assistant and the research team would know that it was not appropriate and safe to visit (probably because the husband was at home). The research assistant was to pose as a trader so that nobody would understand what was happening, in case someone else picked up the respondent's phone call.

The second means devised to overcome the challenge of data collection was for the Senegalese female research assistant to visit the respondent while the team waited nearby. This was because she had familiarized herself with the respondents immediately after the Senegalese woman leader introduced the team to the Senegalese women in the study location. In addition, her ability to speak fluent Wolof, Yoruba, and English endeared her to the respondents and she was quickly trusted by them. She was meant to discuss the high cost of commodities whenever she visited, before tactfully inquiring if it was appropriate to conduct the interview. When the respondent confirmed that her husband was not at home and it was safe and appropriate to conduct the interview, the research assistant would quickly invite the waiting research team but, when it was not safe and appropriate for the interview, the research assistant would send an SMS to the research team with the caption "Negative." These strategies were employed to ensure the safety of the researchers and the respondents in order to conduct the interview when the husbands were not at home.

\section{Results}

\subsection{Characteristics of Study Participants}

This study was based on the experiences of 20 Senegalese women who currently lived in Nigeria. Their age at marriage was from 14 to 21 years, and their current age range from 20 to 56 years. The participants had a basic formal education, had lived in Nigeria for at least 10 years at the time of the interview, and were all married.

\subsection{Ethnicity and Marriage}

We examined the data that were obtained from Senegalese women who lived in Nigeria to understand their marital and family experiences. Ethnic group affiliation and cultural beliefs influence the choice of marriage and family life in many countries in the world, especially in Africa. This practice is associated with the cultural perception of women and their associated responsibilities within the family. Women reported that they 
were persuaded to marry their mate and that they never knew their mate before they were flown to a foreign country to meet their would-be spouse. However, they did not resist such a move because of family pressure and cultural practices that approve of arranged marriage within the same ethnic group. This study was especially interesting because it focused on the experiences of women in arranged marriages within the same ethnic group yet who were residing in different countries. This form of marriage has long-term implications for family life. We inquired about the experiences of women and their reasons for acceptance of arranged marriages. A respondent reported:

My family suggested that I marry someone from a particular family. Therefore, when the arrangement was made, my family had to transport me to Nigeria to meet my husband. I never knew him before meeting him. Initially, I thought he was my uncle when we got to his place as I was expecting to meet someone young, only for him to be introduced as my husband. (W1)

Respondents were of the opinion that marriage to someone from the same ethnic group strengthened the ties within families. In Africa, arranged marriage is widely practiced, and it is a way of life that influences behavior within the family. Respondents perceived that arranged marriages helped to sustain family beliefs and traditions. For instance, they assisted the children within the family to speak their indigenous language, regardless of where their birth occurred. A respondent expressed this perception:

When you marry a partner from your ethnic group, both of you communicate with your indigenous language within the home. This helps children to speak and communicate with the indigenous language as well. This thought, which I had preconceived, made me not to resist when I was link to marry someone I did not know and had never met. (W2)

Marriage within the same ethnic group helps to sustain the culture, norms, and way of life of a particular ethnic group. This is significant when the individuals reside in a foreign country. In order not to be overshadowed by the indigene of the land where they reside, many foreigners marry from their own ethnic affiliation. Therefore, it is essential to marry someone from the same ethnic group in order to maintain and sustain a given culture. This view was captured by a respondent who noted:

Marriage between people from the same ethnic group promotes the sustainability of the culture and norms of the group. It also gives you security in a foreign country, as you are likely to form a group or association. This made me not to resist arranged marriage by my family. (W3)

\subsection{Wife Battering among Immigrants}

Irrespective of the joy associated with marriage between people from the same ethnic group, an irreversible condition was common among Senegalese women who lived in Nigeria, as data indicated that they experienced violence within their homes. The respondents encapsulated this idea:

My husband frequently beats me. He is arrogant, harsh, and hot temper. The last time I was beating, I could not stand up for about 2 days as I was rush to the hospital by neighbours. I now have morbid fear for him as he often look for excuses to punch me when I make any mistake. (W4)

Intimate partner violence leads to low self-esteem among women in an environment characterized by patriarchy. A respondent buttressed this when she stated:

Marriage is a trap. It is like a prison where women are enclosed and susceptible to intimate partner violence. Most women's opinion is not relevant within the household as they are relegated to the kitchen. This is especially common in a household where women contribute little or nothing financially. (W5)

The situation was worse as family members were not within reach to console a woman who lived in a foreign country. This made living in a foreign country very frustrating 
and a serious challenge. Younger women experienced trauma and depression due to the unavailability of parents to administer advice and guidance when they experienced IPV. A respondent explained further that:

Many of us here are like a slave. We are all hiding our emotions and living in pain. Sometimes I suffer from constant headaches, pain, and depression. While few of us have adjusted to the frequent domestic violence, the harsh economic reality has made our husbands very tough and this is reflected by their arrogance as indicated by the frequent beating of women. (W6)

Patriarchy is widely practiced in Africa where husbands have been culturally perceived as superior to their wives. In addition, divorce is not encouraged within the indigenous society and several efforts are exerted to avoid it. This means women are likely to remain in marriage despite IPV, as it is a shame to be referred to as a divorcee in Africa. A respondent noted:

Nobody wants the community to gossip about her as a divorcee. Society perceives divorcee negatively and parents do not want people to label their children as a divorcee as well. These prompt women to endure a marriage even when beating and abused by their husbands. In fact, it is not our culture to get divorce. (W7)

Women did not desire to divorce or separate from their husbands despite severe violence within the home. The experiences of Senegalese women were not synonymous with them alone as women from other nations also experienced intimate partner violence.

\subsection{Nature of Abuse Experienced by Women}

It should be noted that violence and abuse come in different forms, and, as emphasized by feminist theory, it is intrinsically designed to control women. This is made possible as a result of power inequality, which is embedded in the society. Reports from the respondents showed that abuse could be meted out in subtle or violent ways that cause pain to the victims. For instance, a respondent noted:

My husband physically beats me as if I am a small child. I recall some time ago when I was multitasking in the house. I was ironing clothes in my room and at the same time, I was preparing food for home consumption. Immediately I completed the task of ironing the clothes, I unplugged the socket and drop it on the floor after removing it from the electricity wall socket. I then proceed to the kitchen to continue with the preparation of food. Unfortunately, my youngest son touched the hot iron steel and it burnt his fingers. When my husband returned from work and he was informed about the accident, he became very upset to the extent that he slapped me. When I attempted to explain further how the mistake occurred, he flogged me with his belt. I cried profusely and felt so disappointed. (W8)

Physical violence caused pain and disappointment to the victims. Another respondent narrated her experience when she stated:

There was a time when I offered my husband food to eat. As he was eating, he grid his teeth on stones. It was an unfortunate incidence because I carefully selected the beans. My husband was seriously angry with me to the extent that he threw the food remnants on my body. When I attempted to apologize, he slapped me on the face twice. He even threaten to divorce me if I make such mistake again. (W9)

These experiences were an indication that women experienced physical violence at home. However, the violence against women was not exclusively physical, as women narrated incidents of economic violence. A respondent reported:

One of the bane I endure each day is that my husband do not wants me to work secularly to earn income and he does not give me enough money for food and household upkeep. For instance, the nature of his job makes him travel away 
from home for weeks or months. During these periods when he goes away, he does not give me adequate fund to feed the children and myself. I have to beckon on neighbours for food and I also purchase food stuff on credit. Although he repays the debt when he arrives, the experience is not ideal. He makes me over depend on him for everything which is dangerous. He has vehemently oppose my efforts to start up a trade. (W10)

Another woman narrated a similar experience of economic violence within the context of family life when she said:

I have passion for trading. I grew up in a home where my father and mother are traders. But my experience has been different as my husband wants me to remain a full-time house wife. He has resisted my efforts to start up a small-scale business. He wants me to completely depend on him for upkeep. At times, he forcefully take my money or savings, and threaten me not to challenge him or his authority at home. (W11)

Control of the household economy by men was a salient way to control women. This is because economic control might strengthen men's decision-making power within the home. The above experiences show that intimate partner violence can be physical and economical within the home. Aside from these two forms of violence, the interview report further showed that women experienced sexual violence from their husbands. A respondent reported:

My husband has uncontrolled sexual passion. The birth spaces between my children is less than 18 months. He just kept me busy with reproductive activities and childcare. Whenever I tell him I want to rest or I am not in the mode for sexual activities, he forcefully open my legs and have unprotected sexual intercourse with me. He has refused to use contraceptive and he does not wants me to use contraception as well. He often remind me that he has paid for my bride price, thus, I should not resist his sexual urge and demands. (W12)

Another respondent narrated a similar incident when she said:

Even when I was breastfeeding, my husband would not allow me to rest as he is always urging and burning to have sexual intercourse with me. At first, he threatens me that he would go outside to do it if I resist him. I thought he was joking until I heard from a neighbor that my husband impregnated a little girl down the street. I inquired from him and he affirmed it, and when I agitated against his action, he threw my clothes outside his house and poured water on them. It was an embarrassment that period. (W13)

This shows that women were perceived as objects of sex, as a few men did not want to be resisted when craving it. In fact, as shown by the experiences of the women above, women at times were forced to have sexual intercourse with their husbands against their will, regardless of the health implications it had for them, especially breastfeeding mothers who may be exposed to conception and the risk associated with short birth intervals.

Aside from physical, economic, and sexual violence, a few women opined that their personalities had been managed by their husbands. This was a form of social control and they narrated it by stating that:

For me my husband is particularly concern about controlling the way I dress. Before going out to do anything, I need to get approval on my clothes. At times, I change clothes more than five times because he disapproves of the earlier ones I wore. He desires my clothes to cover all my body so that I don't get admired by another person. It is intimidating and dehumanizing my sense of humour and personality but I am constraint to do otherwise. (W14)

Another respondent narrated a similar incident when she reported that:

I cannot attend any social gathering, party, or ceremony, except my husband accompany me or we were both invited. My husband had abused me with 
remarks such as prostitute when I attended an occasion without him. I recalled an incidence that occurred when we just got married; my neighbor invited me to a wedding ceremony that I attended. When I got back home, my husband verbally abused me and accused me of going out for a date with someone else. My husband was very angry to the extent that he called me names like a harlot. He even tore my clothes in the public and threw away my hair wig. I had to run to my neighbours house for safety. It was the neighbours that pleaded with him and calm the situation. (W15)

The narrative above highlights that women experienced social, sexual, economic, and physical violence within the family. Contextually, intimate partner violence manifested in different forms, yet the intrinsic aim was to control women's attitudes and behavior.

\subsection{Impact/Effect of Intimate Partner Violence on Women}

Contextually, intimate partner violence had severe implications for women. Since violence against women comes in different forms; the impact it had as well was felt differently among women. A respondent reported that she experienced mental stress when she was sexually abused. She noted:

I attempted suicide when I learnt that my husband had sex with someone else on our matrimonial bed. The height of the pain was when he impregnated someone else in the neighbourhood. I lost my memory, as I was surprise to find myself in the hospital. I was later informed that I fainted. The shock almost paralysed my right leg. I survived the mental stress by God grace, as I had to leave the home for 6 months to regain my sanity. It was not a nice experience. (W16)

This shows that sexual violence and abuse could have severe health implications on the victims, as it could claim their lives and increase the death rate due to intimate partner violence.

Another respondent narrated her ordeal when she said:

As a graduate, I do not like the idea of my husband dictating and molding my personality by determining my dressing and grooming. There is absolutely nothing I can do to change my current predicament but it makes me lose my self-confidence as an adult. I cannot think for myself when it comes to grooming. It is frustrating, honestly. (W17)

Another respondent noted:

Life could be boring when you are relegated to the kitchen. My creativity skills is diminishing, as I am constraint to use it outside the home. My life itself is boring at the moment and I hope it changes soon. Since I have to wait for my husband for every decision at home and anything contrary results to physical and verbal abuse, it does not make me think properly anymore. (W18)

The above narrative highlights that violence against women had mental and psychological effects. A respondent noted below:

I have adjusted to the experience of living with my husband. As I speak to you, my husband's voice is like thunder to me. I have strong phobia for him due to the frequent punch and slaps he had given me. It is as if I now live in fear of the unknown. (W19)

Another respondent reported a similar incident when she said:

My dear I am caged/trap here all on the name of marriage. I cannot socialize with neighbours and friends because my husband is always suspicious of my every move. He wants to control my decisions in life. In fact, I cannot take any decision without consulting him. The reality is that I cannot change the situation. (W20)

The above narratives show that intimate partner violence resulted in mental, psychological, social, and personality implications for women. Women suffered from constant fear and traumatic experience due to violence within the home. 


\subsection{Factors Contributing to Intimate Partner Violence}

It is remarkable to know that women remained in marriage despite violence and other challenges. We engaged the women from Senegal who lived in Nigeria to understand their reasons for not leaving their violent partners. We found that some women who experienced IPV were financially constrained as many of them were not engaged in any economic activities. In addition, many of them did not know the route to travel back to their home country, since they had been escorted to Nigeria. A respondent reported:

I do not have money to travel back to my family in Senegal. I am a full-time house wife as I am not currently working and my husband do not want me to own a shop to start a business. He believes that engaging in economic activities would expose me to promiscuity. In addition, my husband cannot adequately cater for our household and there is serious hunger. He beats me violently when I attempt to discuss the issue with him. (W8)

This shows that poverty was an intrinsic factor that made women remain in a violent marriage. Arranged marriages were characterized by several challenges, such as the husband not adequately caring for his household. A respondent noted:

If it were possible to foresee the future, I would not have been married when I did, neither would I have married my husband. My husband neglects me and the children as he always abandons us without money for livelihood. He does not give us money for food whenever he travels to the farm to work and he spends 3 months before coming back. The period of his absence is usually tough for my children and me. This experience is tough and a challenge. When I attempt to discuss the issue with him, he beats me with a belt. (W9)

The pain experienced by women in violent marriages is often not documented due to cultural constraints that prevent women from speaking out. Therefore, many women endured violent relationships in marriage for a long time. Promiscuity was a common incidence among Senegalese nationals who resided in Nigeria as many women complained that some of their partners flirted with younger women, and they were forbidden from speaking because their culture permitted polygyny. For instance, a respondent said:

My husband impregnated my cousin who came to assist me after I gave birth.

I was shocked and speechless. When I mustered up the courage to discuss the issue with him, I was beaten. None of the people from my ethnic group that came around was able to caution him but rather, I was blamed for complaining and advise to endure. It was a terrible experience. (W10)

Intimate partner violence was not synonymous with Senegalese women who lived in Nigeria, however, contrary to the widely held perception that marriage between people from the same ethnic group is free from violence. This study documented the experience of intimate partner violence using experiences of Senegalese women living in Nigeria. Violence within the home demoralized women and diminished their self-esteem. This had negative implications for their health and well-being. A respondent noted:

I live in fear as the presence of my husband at home bread further fear. This is because I do not know what will be the next complaint that would warrant him to beat me. I cannot make any meaningful decision in his absence, as any opinion contrary to his is a challenge. I am like a happy slave who must do everything to sustain my marriage. (W11)

The experiences of Senegalese women who lived in Nigeria showed that marriage within the same ethnic group was not devoid of violence. This had implications for their health and social well-being.

\section{Discussion}

This study was designed to (1) examine the factors contributing to intimate partner violence among Senegalese women living in Nigeria; and (2) know the extent to which 
intra-ethnic marriage influences the practice of intimate partner violence in sub-Saharan Africa. The results provide evidence that intimate partner violence occurred in intra-ethnic marriages in sub-Saharan Africa. Several social and cultural factors were responsible for the incidence of intimate partner violence. These included patriarchy, gender and social norms, permissive culture, economic pressure, unemployment, and poverty. Intimate partner violence was not associated with ethnic group affiliation. Rather, it was a social problem that endangered the health, well-being, and lives of women. Many women were trapped in a marriage and could not leave a violent home due to social and cultural norms that perceived divorced women negatively. In addition, many of the Senegalese women interviewed in this study did not know the route to their home country, thus making it difficult for them to leave their violent partners.

Sociological studies have shown that inter-ethnic marriage is responsible for the high prevalence of divorce rates in mainstream society (Amato 2010; Hohman-Marriott and Amato 2008). Thus, inter-ethnic marriage is a deviation from societal norms and it is susceptible to intimate partner violence, household conflict, and marriage instability (Chartier and Caetano 2011). These studies reported that intra-ethnic marriages are not confronted with the problems stated above. However, this study found that while earlier reports may be contextually applicable to other continents where such studies were conducted, they are not in tandem with the reality in Africa due to the prevalence of patriarchy and cultural norms that influence couples' conjugal behavior. By using migrants from Senegal who resided in Nigeria, this study found that IPV exists within intra-ethnic marriage with grave implications. Therefore, ethnicity may not completely determine the prevalence of IPV in Africa due to the complex driving forces behind it.

Delaney (2001) noted that culture aids the underlying significance of marriage within the context of patriarchy. This study corroborates such a report by arguing that intraethnic marriage inadvertently fosters strong ties within families but it does not curtail the incidence of IPV due to the complex nature of its driving forces in the society. In addition, intra-ethnic marriage helps in the socialization of children using indigenous language, thus transmitting indigenous language from one generation to another. This finding is in tandem with the report by Fusco (2010) that language is an instrument of cultural continuity and the use of it for communication with children fosters transmission of cultural norms from one generation to another.

Senegalese immigrants encourage endogamy as a source of security for themselves (while living in a foreign land). This social dimension influences actions, behavior, and passion for importing females for marriage. Theoretically, ethnic capital affects immigrant children as they are more likely to follow a sociation that is different from the host country (Borjas 2006). Immigrants choose their associates based on ethnic affiliation and the socialization process that forms human capital. In this study, it was found that ethnic group and social circle are associated with the choice of marriage. Distance or living in a different country does not change ethnic orientation and choice of marriage. Previous studies by Furtado and Theodoropoulos (2011) noted that ethnic preferences of people living far from their enclave yet remaining closely attached to their ethnic groups, can be captured by their choice of marriage to someone of the same ethnicity. Thus, marriage to someone of the same ethnic country of origin remains an important source of ethnic attachment. Lazear (1999) reported that this is made possible by shared culture, beliefs, and way of life. However, Stark (2007), in his book titled Coercive Control: The Entrapment of Women in Personal Life, showed how culture, norms, beliefs, and societal values could be an invisible cage used to control women.

Furthermore, Leonard and Eiden (2007) noted that poverty and social exclusion can result in an aggressive lifestyle. This study corroborated this report as women narrated the high level of aggression often exhibited by their husbands. Many women agreed that their husbands' aggressive attitude at home was due to work-related stress and pressure. The migration of Senegalese to Nigeria is mainly to search for a better life. However, they often struggle to get a good source of livelihood, especially during the early period of their arrival 
to Nigeria. Therefore, lack of a good source of income and subsequent transfer of aggression was likely responsible for intimate partner violence among Senegalese immigrants. In a study conducted in Nigeria, Ayodeji and Basirat (2020) opined that poverty and lack of basic needs increased the level of male aggression to female. Other studies (TandrayenRagoobur 2020; Abramsky et al. 2019) have shown a similar correlation between limited financial resources and increased male aggression.

The situation is made worse by the permissive culture and patriarchy that portrays men as superior to women. This implies that the combined effect of social factors such as economic inequality, poverty, culture, and patriarchy influences the prevalence of intimate partner violence (IPV). Intra-marriage and intermarriage are not exclusively the causes of intimate partner violence (IPV), yet they have been implicated as a pathway to IPV in Africa. Sociocultural norms explain that those who occupy an inferior position in the society are often marginalized and violently abused, as reflected by intimate partner violence among immigrants. Those with inferior positions (women) cannot fight against the existing family and societal institutions because it is a shared norm that has endured over time.

Feminist theory argued that violence against women is due to patriarchy, which preaches male domination over females. Intimate partner violence has a social and historical undertone that permeates society from generation to generation (Duffy and Momirov 1997). Feminist theory opined that gender-based violence such as intimate partner violence (IPV) is a tactic to control females and uphold male superiority. This study is consistent with the literature (Bunge 2000; Jewkes 2002) emphasizing that poverty, unemployment, patriarchy, permissive culture, promiscuity, and other underlying complex social forces make women prey to intimate partner violence in Africa. Patriarchy subtly permits intimate partner violence without the knowledge of actors and victims who have been coerced and enveloped by existing culture to think that this abnormality is the norm of the society.

Intimate partner violence among the Senegalese migrants that reside in Nigeria is often resolved through informal means by household neighbors and ethnic group members. This finding corroborated a report by Nwosu (2006) in a study conducted in Canada among Nigerian immigrants. He found that Nigerian immigrants are more likely to explore informal means to resolve domestic violence. In a similar study conducted in the United State of America, Kalunta-Crumpton and Onyeozili (2011) observed that to resolve intimate partner violence, Nigerian immigrants were more likely to seek informal support from family and non-family members such as friends, community and religious leaders. However, these informal measures favor cultural norms like patriarchy, which further subjects women to exploitation.

\section{Limitation}

This study was conducted among Senegalese women who live in Oyo State, Southwest Nigeria. A replication of the study in another location may yield different results. In addition, this was a qualitative study aimed at the interpretative understanding of the experiences of immigrants using Senegalese women as a case study. The results from a quantitative study using the same variables are not clear. In studies based on deliberate sampling, the interpretation of results is limited to the cases studied and generalizations are not valid. It is the internal validity of the research results (Tongco 2007). The results of this study are not representative of any whole population, nor can they be generalized. The knowledge obtained concerns merely the analyzed phenomenon in the specific context and it cannot be "transferred" (Shenton 2004). However, it is strongly believed that the experiences of Senegalese women in Nigeria are a reflection of immigrants within subSahara Africa as regards intimate partner violence.

\section{Conclusions}

Our study found that intimate partner violence is exclusive to neither inter-ethnic marriage nor intra-ethnic marriage. Data from this study show that arranged and forced marriage was inherently a contributor to intimate partner violence among Senegalese im- 
migrants who live in Nigeria, although intra-ethnic marriage fosters unity and cooperation among immigrants. However, intra-ethnic marriage sustains cultural norms, values, and family ties. These social and cultural norms in a patrilineal society aid the practice of gender norms and inequality, thus making it a challenge to achieve Sustainable Development Goal 5 within the context of sub-Saharan Africa. Social and cultural norms cum patriarchy propel the subjugation of women as second-class citizens within the home. Consistent with this report, many immigrant women remain in the violent home because society perceives marital instability and divorce negatively.

In addition, a sizable number of immigrants do not know the route to travel back to their country of origin, nor do they have the financial strength to embark on such a trip. These women have been trapped in the marriage for the sake of their children, their family name and reputation, and cultural norms that constrain them from separation and divorce. Furthermore, immigrant women remain in marriage despite the violent experience that results in loneliness, depression, and severe health challenges. Conscientious efforts should be made by community leaders to curtail the prevalence of intimate partner violence. Community efforts are most appropriate since informal measures are often utilized to resolve family crises in the context of sub-Saharan Africa.

Author Contributions: Conceptualization, A.O. and O.C.; Data Curation, O.C.; Formal analysis, A.O. and O.C.; Funding acquisition, A.O.; Investigation, A.O. and O.C.; Methodology, A.O. and O.C.; Supervision, A.O.; Validation, O.C.; Writing—original draft, A.O. and O.C.; Writing—review \& editing, A.O. and O.C. All authors have read and agreed to the published version of the manuscript.

Funding: This research received no external funding.

Institutional Review Board Statement: The study was conducted according to the guidelines of the Declaration of Helsinki, and approved by the Institutional Ethics Committee of Social Sciences and Humanities of University of Ibadan with assigned number UI/SSHEC/2017/0025.

Informed Consent Statement: Informed consent was obtained from all subjects involved in the study.

Conflicts of Interest: The authors declare no conflict of interest.

\section{References}

Abbott, Pamela, Melissa Tyler, and Claire Wallace. 2005. An Introduction to Sociology: Feminist Perspectives, 3rd ed. London: Routledge. Abramsky, Tanya, Shelley Lees, Heidi Stockl, Sheila Harvey, Imma Kapinga, Meghna Ranganathan, and Saidi Kapiga. 2019. Women's income and risk of intimate partner violence: Secondary findings from the MAISHA cluster randomized trials in North-Western Tanzania. BMC Public Health 19: 1108. [CrossRef] [PubMed]

Allsworth, Jenifer E., and Marlene B. Goldman. 2017. Population at Special Health Risk: Women, 2nd ed. Kansas City: International Encyclopedia of Public Health, pp. 276-85.

Amato, Paul. R. 2010. Research on divorce: Continuing trends and new developments. Journal of Marriage and Family 72: 650-66. [CrossRef]

Ayodeji, Olowoporoku, and Atijosan Ayobami Basirat. 2020. Empowered but violated: Study of intimate partner violence and women labour force participation in Nigeria. Journal of Economic and Social Research 19: 111-20.

Berg, Marc. 2001. Implementing information systems in health care organisations: Myths and challenges. International Journal of Medical Informatics 64: 143-56. [CrossRef]

Bishop, Charlotte, and Vanessa Bettinson. 2018. Evidencing domestic violence, including behaviour that falls under the new offence of "controlling or coercive behaviour". International Journal of Evidence E Proof 22: 3-29.

Borjas, George. J. 2006. Native internal migration and the labour market impact of immigration. The Journal of Human Resources 50: 72-93.

Braun, Virginia, and Victoria Clarke. 2006. Using thematic analysis in psychology. Qualitative Research in Psychology 3: 77-101. [CrossRef]

Btoush, Rula, and Jacquelyn C. Campbell. 2009. Ethical conduct in intimate partner violence research: Challenges and strategies. Nursing Outlook 57: 210-16. [CrossRef]

Bunge, Mario. 2000. Systemism: The alternative of individualism and holism. The Journal of Socio- Economics 29: 147-157. [CrossRef]

Charmaz, Kathy, and Karen Henwood. 2017. Grounded Theory Methods for Qualitative Psychology. In The SAGE Handbook of Qualitative Research in Psychology. Newcastle: SAGE, p. 238.

Chartier, Karen G., and Raul Caetano. 2011. Intimate partner violence and alcohol problems in interethnic and intraethnic couples. Journal of Interpersonal Violence 27: 1780-801. [CrossRef] 
Chikhungu, Lana Clara, Mark Amos, Ngianga Kandala, and Saseendran Palikadavath. 2019. Married women experience of domestic violence in Malawi: New evidence from a cluster and multinomial logistic regression analysis. Journal of Interpersonal Violence 2019: 1-12.

Cockburn, Cynthia. 2004. The continuum of violence: Agender perspective on War and Peace. In Sites of Violence: Gender and Conflict Zones. Edited by Giles W. and Hyndman J. Kos Angeles: University of California Press, pp. 1-38.

Conway, Maree. 2016. A Feminist Analyses of Nuclear Weapons: Par 1-Hegemonic Masculinity. A Feminist Foreign Policy. Available online: https:/ / www.afeministforeignpolicy.com/blog/2020/12/12 (accessed on 24 December 2020).

Corradi, Consuelo, Chaime Marcuello-servos, Santiago Boira, and Shalva Weil. 2016. Theories of femicide and their significance for social research. Current Sociology 64: 975-95. [CrossRef]

Delaney, Kevin. 2001. Teaching Mathematics Resourcefully. In Issues in Mathematics Teaching. London: Routledge Falmer.

Devries, Karen M., Joelle Y. Mak, Claudia Garcia-Moreno, Max Petzold, James C. Child, Gail Falder, Lim Stephen, Loraine Bacchus, Vos Theo, Watts Charlotte, and et al. 2013. The global prevalence of intimate partner violence against women. Science 340: 1527-28. [CrossRef] [PubMed]

Duffy, Ann, and Julianne Momirov. 1997. Family Violence: A Canadian Introduction, 2nd ed. Available online: https://books.google. com.ng/books/about/Family_Violence_A_Canadian_Introduction.html?id=X4LHWuoCbOAC\&redir_esc=y (accessed on 24 December 2020).

Ellsberg, Mary, Lori Heise, Rodolfo Pena, Sonia Agurto, and Anna Winkvist. 2001. Researching domestic violence against women: Methodological and ethical considerations. Study Family Plan 32: 1-16. [CrossRef] [PubMed]

Fryer, Roland G. 2007. Guess who's been coming to dinner? Trends in interracial marriage over the 20th century. Journal of Economic Perspectives 21: 71-90. [CrossRef]

Furtado, Delia, and Nikolaos Theodoropoulos. 2011. Interethnic marriage: A choice between ethnic and educational similarities. Journal of Population Economics 24: 1257-79. Available online: http:/ /www.jstor.org/stable/41488351 (accessed on 26 November 2020).

Fusco, Rachel A. 2010. Intimate partner violence in interracial couples: A comparison to White and ethnic minority monoracial couples. Journal of Interpersonal Violence 25: 1785-800. [CrossRef]

Gage, Anastasia J. 2005. Women's experience of intimate partner violence in Haiti. Social Science E Medicine 61: 343-64. [CrossRef]

Goodrum, Sarah, and Jennifer L. Keys. 2007. Reflections on two studies of emotionally sensitive topics: Bereavement from murder and abortion. International Journal of Social Research Methodology: Theory E Practice 10: 249-58. [CrossRef]

Hohman-Marriott, Bryndl, and Paul Amato. 2008. Relationship Quality in Interethnic Marriages and Cohabitations. Social Forces 87: 825-55. [CrossRef]

Jewkes, Rachel. 2002. Intimate partner violence: Causes and prevention. The Lancet 359: 1423-29. [CrossRef]

Kalunta-Crumpton, Anita, and Emmanuel C. Onyeozili. 2011. Nigerian women in deadly intimate partner violence in the United States. International Review of Modern Sociology 37: 239-63.

Lazear, Edward P. 1999. Culture and language. Journal of Political Economy 108: 15-40. [CrossRef]

Leonard, Kenneth E., and Rina D. Eiden. 2007. Marital and family processes in the context of alcohol use and alcohol disorders. Annual Review of Clinical Psychology 3: 285-310. [CrossRef] [PubMed]

Magadi, Monica, Martin Gazimbi, Charles Wafula, and Margaret Kaseje. 2020. Understanding ethnic variations in HIV prevalence in Kenya: The role of cultural practices. Health, Culture, and Sexuality, 1-19. [CrossRef] [PubMed]

McCloskey, Laura Ann, Floretta Boonzaier, Sheila Young Steinbrenner, and Theresa Hunter. 2016. Determinants of intimate partner violence in sub-Saharan Africa: A review of prevention and intervention programs. Partner Abuse 7: 277-315. [CrossRef]

Nwosu, Ngozi L. 2006. The experience of domestic violence among Nigerian-Canadian Women in Toronto. Canadian Woman Studies 25: 99-106.

Ranganathan, Meghna, Louise Knight, Tanya Abramsky, Lufuno Muvhango, Tara Polzer Ngwato, Mpho Mbobelatsi, Giulia Ferrari, Charlotte Watts, and Heidi Stöckl. 2019. Associations between women's economic and social empowerment and intimate partner violence: Findings from a microfinance plus program in rural North West Province, South Africa. Journal of Interpersonal Violence. [CrossRef]

Shenton, Andrew K. 2004. Strategies for Ensuring Trustworthiness in Qualitative Research Projects. Education for Information 22: 63-75. [CrossRef]

Stark, Evan. 2007. Coercive Control: How Men Entrap Women in Personal Life. New York: Oxford University Press.

Stark, Evan. 2016. From domestic violence to coercive control in the United Kingdom. Domestic Violence Report 21: 23-6.

Tandrayen-Ragoobur, Verena. 2020. Intimate partner violence and women's labour force participation in Sub Saharan Africa. Community, Work \& Family 23: 19-43.

Tongco, Ma-Dolores C. 2007. Purposive Sampling as a Tool for Informant Selection. Ethnobotany Research E Applications 5: 147-58.

Walby, Sylvia, and Jude Towers. 2017. Measuring violence to end violence: Mainstreaming gender. Journal of Gender-Based Violence 1: 11-32. [CrossRef]

WHO. 2001. Putting Women First: Ethical and Safety Recommendations for Research on Domestic Violence against Women. Geneva: World Health Organization.

WHO. 2003. World Health Organisation Ethical and Safety Recommendations for Interviewing Trafficked Women. Geneva: World Health Organization. WHO. 2007. World Health Organisation Ethical and Safety Recommendations for Researching, Documenting, and Monitoring Sexual Violence in Emergencies. Geneva: World Health Organization. 
WHO. 2013. Global and Regional Estimates of Violence against Women: Prevalence and Health Effects of Intimate Partner Violence and Non-Partner Sexual Violence. Available online: https://apps.who.int/iris/bitstream/handle/10665/85239/9789241564625_ eng.pdf;jsessionid=D135074A4B64017AE10E866A01740E98? sequence=1 (accessed on 26 November 2020).

WHO. 2015. WHO Multi-Country Study on Women's Health and Domestic Violence against Women: Summary Report of Initial Results on Prevalence, Health Outcomes and Women's Responses. Geneva: World Health Organization.

WHO. 2017. Violence against Women: Key Facts. Available online: https://www.who.int/news-room/fact-sheets/detail/violenceagainst-women (accessed on 26 November 2020).

Zembe, Z. Yanga, Loraine Townsend, Anna Thorson, Margrethe Silberschmidt, and Anna M. Ekstrom. 2015. Intimate Partner Violence, Relationship Power Inequity and the Role of Sexual and Social Risk Factors in the Production of Violence among Young Women Who Have Multiple Sexual Partners in a Peri-Urban Setting in South Africa. PLoS ONE 10: e0139430. [CrossRef] [PubMed] 